\title{
Effects of Zinc Amino Acid in Walking Catfish (Clarias macrocephalus) Female Broodstock First Sexual Maturation
}

\author{
Siti-Ariza Aripin ${ }^{1 *}$, Orapint Jintasataporn ${ }^{2}$ and Ruangvit Yoonpundh ${ }^{2}$ \\ ${ }^{1}$ School of Fisheries and Aquaculture Sciences, Universiti Malaysia Terengganu, 21030, Terengganu, Malaysia \\ ${ }^{2}$ Faculty of Fisheries, Kasetsart University, 10900, Bangkok, Thailand
}

\begin{abstract}
This study examines the effects of zinc amino acid (ZnAA) to the first sexual maturity stage in female broodstock of the Walking catfish, Clarias macrocephalus. The different ZnAA levels of Control (0 ppm ZnAA), ZnAA1 (100 ppm ZnAA) and ZnAA2 (200 ppm ZnAA) in the diet was applied to the first sexual maturation female catfish (Availa ${ }^{\circledR} \mathrm{Zn}$, Zinpro Corporation, Eden Prairie, MN USA). ZnAA accumulation, broodstock maturation analysis and breeding performance were evaluated. The ZnAA treatment has significant different in serum, meat and ovary ZnAA accumulation. The ZnAA treatment increased the fecundity, gonadosomatic index, egg diameter and development of oocytes at tertiary yolk stage. In comparison, the ZnAA treatment was insignificant in estradiol level. During artificial fertilization, the ZnAA treatment enhanced the fertilization rate and the larval survival rate. During recovery breeding, ZnAA treatment significantly increased the egg production and larval hatching rate. The optimum level to enhance the Clarias macrocephalus female broodstock first sexual maturation is ZnAA1.
\end{abstract}

Keywords: Zinc amino acid; Maturation; Reproduction; Female; Catfish

\section{Introduction}

Walking catfish (Clarias macrocephalus) is one of the favourite aquaculture species in Southeast Asia especially Thailand. It has a high market value due to its tender flesh and delicious flavour $[1,2]$. Despite being an important aquaculture species, C. macrocephalus population continues to decline due to several issues. C. macrocephalus population has become endangered due to the introduction of Clarias hybrid species and limited supply of wild broodstock caused by over exploitation in aquaculture farming that claimed the natural habitat of this species $[1,3]$. As a result, it has taken a toll in the supply of mature broodstock catfish for artificial propagation. Zinc is an essential trace element that plays an important role as a co-factor of enzymes and is a component of many important metallo enzymes. Hence, zinc is fundamentally important for the functioning of reproductive system [4]. Zinc deficiency will cause retarded growth, delayed sexual development, impaired reproduction in males and females, congenital abnormalities, and low hatching rate [4,5]. According to Salgueiro et al. [6], zinc supplementation is able to improve the infertility in female. Supplemented zinc can be absorbed by intestine and delivered to the liver and becomes zinc protein or zinc metallo thionein [7]. The zinc protein in the liver or vitellogenin is transported via the blood to the ovary in order to enhance the oocytes growth for the developing embryo and larvae after fertilization [8]. Zinc is also involved in the production and secretion of luteinizing hormone (GTH-II), follicle-stimulating hormone (GTH-I) and prolactin [6,9]. Zinc amino acid (ZnAA) is zinc that bind to amino acids ligand. According to Formigoni et al. [10], organic minerals including zinc, is capable to bind with ligand such as amino acids, peptides and proteins. In addition, the organic zinc has higher retention, bioavailability and absorption rate compared to inorganic zinc such as $\mathrm{ZnSO}_{4}$ or $\mathrm{ZnO}$ [11]. Information on the occurrence and metabolic roles of $\mathrm{ZnAA}$ in broodstock maturation and reproductive performance is important in order to initiate and enhance the first sexual maturity of female C. macrocephalus ZnAA fundamental mechanism remains unclear even though there are strong evidences of its roles in enhancing the reproductive performance. In order to enhance the maturation and early embryonic development, it is important to investigate the effects of $\mathrm{ZnAA}$ administration to the first sexual maturity stage in female broodstock of the C. macrocephalus.

\section{Materials and Methods}

\section{Fish and culture condition}

The maiden Clarias macrocephalus female broodstock were obtained from the Fisheries Station of Kham Pheng Phet, Department of Fisheries, Ministry of Agriculture and Cooperative, Thailand. The experiment trial was carried out at the Laboratory of Nutrition and Aquafeed, Department of Aquaculture, Faculty of Fisheries, Kasetsart University, Bangkok, Thailand. Approximately eighteen weeks old catfish were acclimatized and maintained in 500L tanks at the density of $15 \mathrm{ind} / \mathrm{m}^{2} / \mathrm{fish} / \mathrm{tank}$ and were fed with control feed for two weeks prior to the experiment. A total of 45 females (initial weight $63.85 \pm$ $4.97 \mathrm{~g}$ ) were subjected to normal photoperiod ( 12 hours day light) prior to treatment and fed at a level equivalent to $3 \%$ of their body weight. The diet was divided into two equal feedings per day. The fishes were randomly distributed in three treatments (Control, ZnAAl and $\mathrm{ZnAA} 2$ ) and with three replicates. The experiment tanks were continuously aerated to maintain the oxygen supply and the duration of experiment was for eight week.

\section{Experimental diets}

The basal diet was formulated from practical ingredients that contained approximately $22 \%$ fishmeal, $35 \%$ soybean, $1 \%$ spirulina, $12 \%$ wheat flour, $11.8 \%$ tapioca, $5 \%$ ricebran, $2 \%$ fish oil, $3 \%$ soy oil, $1.2 \%$ mineral premix, $2 \%$ soy lecithin, $1.5 \%$ calcium phosphate, $1 \%$ attractant, $2 \%$ binder and $0.5 \%$ vitamin premix (Table 1 ). The diet

*Corresponding author: Siti-Ariza Aripin School of Fisheries and Aquaculture Sciences, Universiti Malaysia Terengganu, Malaysia, E-mail: siti.ariza@umt.edu.my

Received April 07, 2015; Accepted April 15, 2015; Published May 30, 2015

Citation: Aripin SA, Jintasataporn O, Yoonpundh R (2015) Effects of Zinc Amino Acid in Walking Catfish (Clarias macrocephalus) Female Broodstock First Sexual Maturation. J Aquac Res Development 6: 347. doi:10.4172/2155-9546.1000347

Copyright: @ 2015 Aripin SA, et al. This is an open-access article distributed under the terms of the Creative Commons Attribution License, which permits unrestricted use, distribution, and reproduction in any medium, provided the original author and source are credited. 


\begin{tabular}{|l|c|}
\hline Ingredient & Dry weight (\%) \\
\hline Fishmeal & 22.0 \\
\hline Soybean & 35.0 \\
\hline Spirulina & 1.0 \\
\hline Wheat flour & 12.0 \\
\hline Tapioca & 11.8 \\
\hline De oil ricebran & 5.0 \\
\hline Tuna fish oil & 2.0 \\
\hline Soya oil & 3.0 \\
\hline Mineral premix & 0.5 \\
\hline Soy lecithin & 2.0 \\
\hline Calcium phosphate & 1.5 \\
\hline MgSO4.7H2O & 0.1 \\
\hline KCl & 0.6 \\
\hline Attractant & 1.0 \\
\hline Binder & 2.0 \\
\hline Vitamin premix & 0.5 \\
\hline
\end{tabular}

Table 1: Ingredients of the basal diet.

\begin{tabular}{|l|c|c|c|}
\hline Proximate analysis (\%) & Control & ZnAA1 & ZnAA2 \\
\hline Moisture & 3.6 & 3.0 & 3.0 \\
\hline Crude protein & 37.7 & 38.0 & 37.8 \\
\hline Crude Fiber & 9.3 & 9.3 & 9.3 \\
\hline Ash & 1.5 & 1.7 & 1.6 \\
\hline Calcium & 11.6 & 11.7 & 11.8 \\
\hline Phosphorus & 1.8 & 1.9 & 1.9 \\
\hline Ether extract & 1.2 & 1.3 & 1.4 \\
\hline
\end{tabular}

Table 2: Proximate analysis for different ZnAA level in the diet.

also consisted of $37 \%$ crude protein and $9.3 \%$ crude lipid (Table 2). Diets containing $\mathrm{ZnAA}$ (one zinc ion bound to one amino acid ion) were prepared by adding different levels of ZnAA (Availa ${ }^{\circledR} \mathrm{Zn}$, Zinpro Corporation, Eden Prairie, MN USA) to the basal diet. These ZnAA concentrations were $0 \mathrm{ppm}$ (control), $100 \mathrm{ppm}$ (ZnAA1) and $200 \mathrm{ppm}$ (ZnAA2) per kilogram in the diet according to NRC [12].

\section{Zinc analysis}

The ZnAA analysis was performed by using Inductive Couple Plasma-Optical Emission Spectrophotometer (ICP-OES) at Central Laboratory (Thailand) Company Limited. 0.25-2 g of samples were prepared for the analysis. All determinations were made in three replicates. Weighted triplicate of the samples were mixed with $7 \mathrm{ml}$ nitric acid and $1 \mathrm{ml}$ hydrogen peroxide in each flask. Microwave digestion was applied at $220^{\circ} \mathrm{C}$ for 45 minutes. After cooling, the resulting solutions were diluted up to $25 \mathrm{ml}$ in volumetric flasks with deionised water. Blanks were prepared in the same way as the sample but excluding the samples. The prepared samples were injected and analysed in ICP-OES machine. The results were compared with standard curve to determine the $\mathrm{ZnAA}$ concentration [13].

\section{Growth performance}

All female C. macrocephalus were anaesthetised with clove oil and were individually weighted prior and after the experiment to measure the fish growth by using the following formula:

Weight gain $(\%)=($ Final body weight - Initial body weight $) \div$ Initial body weight $\times 100$

\section{Histology}

The histology method was in accordance to Drury and Wallington
[14]. The ovary samples were fixed in $10 \%$ buffered formalin and dehydrated in graded alcohol series. The ovaries were embedded in paraffin wax, cut to four micrometer, stained with hematoxylineosin and observed under Motic microscope (Motic BA210 Digital Laboratory Microscope with Moticam 1000 camera). Staging of female oocytes was performed in accordance to Lubzens et al. [15].

\section{Gonadosomatic index}

The Gonadosomatic Index was determined: GSI $(\%)=100 \times$ ovary weight $\div$ body weight

\section{Estradiol analysis}

Chemiluminometric enzyme immunoassay of estradiol was determined by accordance to Ibrahim and Harabawy [16]. Estradiol analysis was conducted using commercially available immunoassay kit (IMMULITE ${ }^{\circledR}$ Estradiol, Siemens Medical Solution Diagnostic and United Kingdom).

\section{Artificial breeding}

Artificial breeding was conducted with the remaining female C. macrocephalus from each treatment to evaluate the reproductive performance of $\mathrm{ZnAA}$ experiment. The female broodstock were lightly anaesthetized with clove oil and were individually inspected to observe matured fish indication including papilla colouring, abdominal swelling and swollen papilla. A mixture of $30 \mu \mathrm{g}$ buserelin acetate (LHRH analogue) and $10 \mathrm{mg}$ domperidone (dopamine analogue) were induced into one kilogram female broodstock $(0.1 \mathrm{ml}$ mixture for 100 $\mathrm{g}$ females) [17]. Male African catfish milt was obtained from dissected testis as the control male to standardize the male semen quality. The eggs and milt were mixed for fertilization and the fertilized eggs were then transferred to the hatching tanks for incubation.

\section{Fish reproductive characteristics}

Egg production, fertilization rate, hatching rate, gonadosomatic index (GSI) and survival rate (seven days old) of the larvae were investigated after the artificial fertilization. Egg production was estimated by direct counting of sub-sample of fertilized eggs in the female ovaries [18]. Oocytes diameters were measured from fresh ovarian tissue with Motic microscope (Motic BA210 Digital Laboratory Microscope with Moticam 1000 camera). Fertilization rate, larval hatching rate and larval survival rate were determined in accordance to Unuma et al. [19]. A recovery breeding was conducted a month later to assess the recovery breeding performance with similar parameters used in the initial breeding session.

\section{Statistical analysis}

Statistical analysis was performed using SPSS software. Data were analysed by one-way ANOVA (analysis of variance) and by the Duncan test which analyses the significant differences among means. The means comparisons significance was tested at $\mathrm{P}<0.05$ [20].

\section{Results}

The C. macrocephalus female broodstock were subjected to $\mathrm{ZnAA}$ accumulation analysis at the end of the experiment trial. $\mathrm{ZnAA}$ concentrations in serum, meat and ovary were significantly different between the treatments with $P$ value of $0.006,0.013$ and 0.03 respectively (Figure 1 and Table 3 ). However, there were no statistical differences for liver, bone, egg and total tissue with the $\mathrm{P}$ value at 0.07 , $0.9,0.1$, and 0.8 , respectively (Table 3 ). Dietary ZnAA treatment did not significantly affect the weight gain with the mean weight gain 

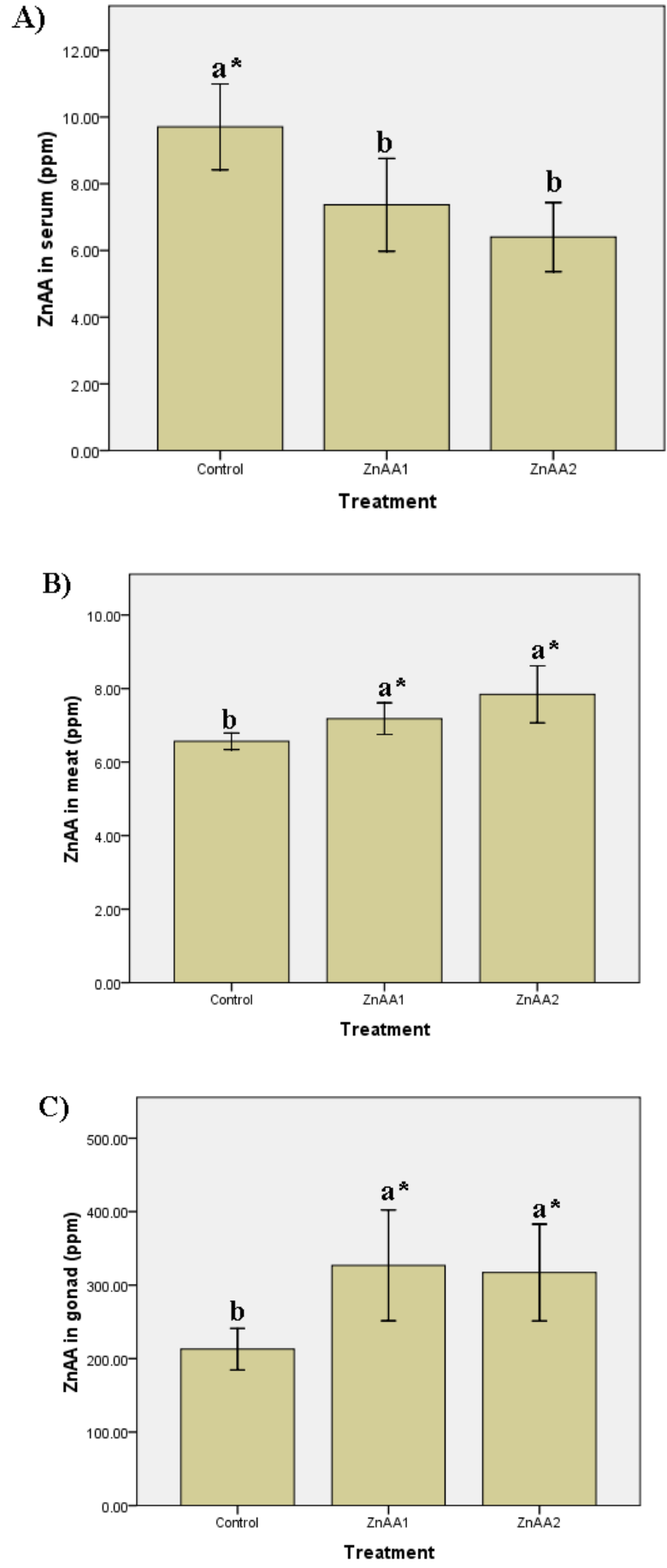

Figure 1: ZnAA concentration in serum $(A)$, meat $(B)$ and ovary $(C)$ of female $C$. macrocephalus after eight weeks of ZnAA treatment. Values are expressed as mean \pm SEM $p<0.05$.

ranged from $10.3-14.2 \%$ with the value at $\mathrm{p}=0.6$. Similar result was found in estradiol profile $(\mathrm{p}=0.4)$ where the estradiol profile was not significantly different between treatments (Table 4). In histological analysis, most ovaries in the control group contained the highest percentage of peri-nucleolus stage (PNS) where the percentage was 51.5\% (control), 28.7\% (ZnAA1) and 20.8\% (ZnAA2) (Figure 2 and
Table 4). Differences in ovarian histology between the ZnAA treatments after eight weeks were highest in the ZnAA2 group for tertiary yolk stage (TYS). The well-developed oocytes at tertiary yolk stage (TYS) were $15.5 \%$ (control), 50.5\% (ZnAA1) and 54.6\% (ZnAA2) (Figure 2 and Table 4). After the experiment trial, there were significant increase in the gonadosomatic index (GSI), fecundity, and egg diameter in the presence of $\mathrm{ZnAA}$ treatment with the $\mathrm{P}$ value at $0.002,0.025$, and 0.001 , respectively (Figure 3 and Table 4). The significant difference in GSI, fecundity, egg diameter and also the prominent evidence in histology

\begin{tabular}{|c|c|c|c|}
\hline Control & ZnAA1 & ZnAA2 & $P$ value \\
\hline $9.70^{\mathrm{a}} \pm 1.5$ & $7.37^{\mathrm{b}} \pm 1.7$ & $6.40^{\mathrm{b}} \pm 1.2$ & 0.006 \\
\hline $6.56^{\mathrm{b}} \pm 0.3$ & $7.18^{\mathrm{a}} \pm 0.5$ & $7.84^{\mathrm{a}} \pm 0.9$ & 0.013 \\
\hline $25.34 \pm 0.9$ & $29.60 \pm 6.5$ & $23.51 \pm 3.2$ & 0.07 \\
\hline $30.43 \pm 4.4$ & $31.07 \pm 3.2$ & $30.83 \pm 17.8$ & 0.9 \\
\hline $55.09 \pm 7.0$ & $52.65 \pm 2.8$ & $49.44 \pm 2.4$ & 0.1 \\
\hline $212.81^{\mathrm{b}} \pm 34.5$ & $326.88^{\mathrm{a}} \pm 92.2$ & $317.20^{\mathrm{a}} \pm 80.6$ & 0.03 \\
\hline $140.35 \pm 29.6$ & $142.42 \pm 36.2$ & $133.35 \pm 35.7$ & 0.8 \\
\hline
\end{tabular}

a,b Values with different superscripts in a row differ significantly $(P<0.05)$.

Table 3: ZnAA concentration in serum, meat, liver, bone, egg and ovary with different $Z n A A$ levels (mean $\pm S D$ ).
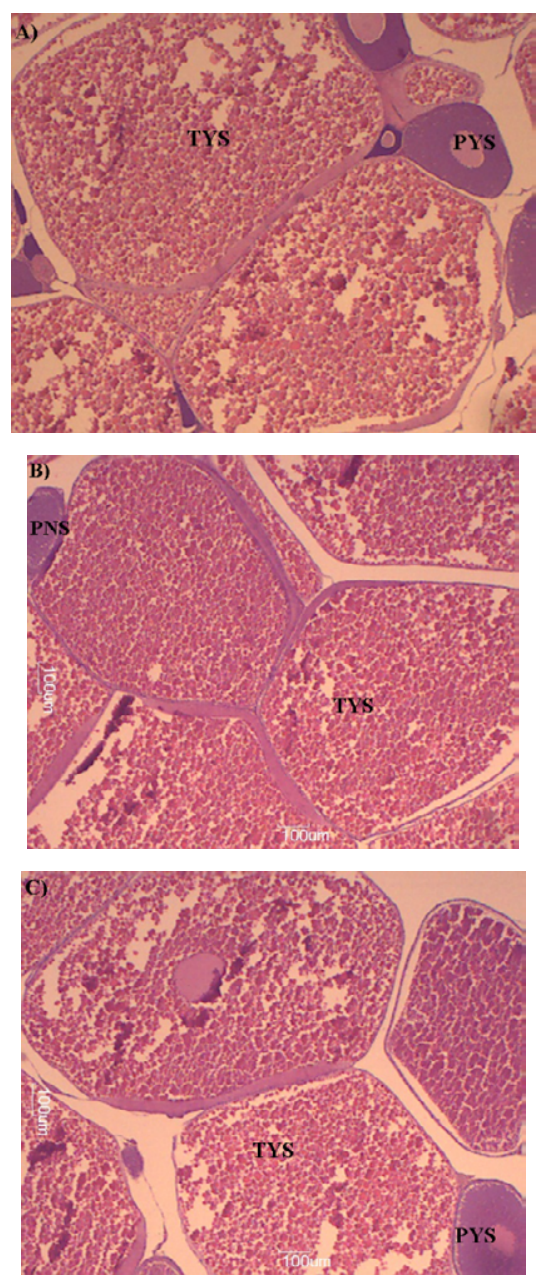

Figure 2: Effect of ZnAA treatment on ovarian histology of the $C$. macrocephalus. Cross section of an ovary of fish treated with control (A), ZnAA1 (B) and ZnAA2 (C). PNS; peri-nucleolus stage, PYS; primary yolk stage, TYS; tertiary yolk stage. Scale bar $=100 \mu \mathrm{m}$. 


\begin{tabular}{|l|c|c|c|}
\hline Treatment & Control & ZnAA1 & ZnAA2 \\
\hline Weight gain $(\%)$ & $10.3 \pm 13$ & $12.8 \pm 10$ & $14.2 \pm 8$ \\
\hline Estradiol $(\mathrm{pg} / \mathrm{ml})$ & $486.7 \pm 151$ & $634.7 \pm 191.5$ & $1812 \pm 2215$ \\
\hline Histology tertiary yolk stage (TYS) & $15.5 \%$ & $50.5 \%$ & $60.3 \%$ \\
\hline Histology peri-nucleolus stage (PNS) & $51.5 \%$ & $28.7 \%$ & $20.8 \%$ \\
\hline Gonadosomatic index $(\%)$ & $5.61^{\mathrm{b}} \pm 0.44$ & $9.03^{\mathrm{a}} \pm 2.14$ & - \\
\hline Fecundity $($ egg/g) & $3034.1^{\mathrm{b}} \pm 329$ & $4955.3^{\mathrm{a}} \pm 2028$ & 0.4 \\
\hline Egg diameter $(\mu \mathrm{m})$ & $1448.4^{\mathrm{b}} \pm 79$ & $1520.3^{\mathrm{a}} \pm 132.8$ & $5756.5^{\mathrm{a}} \pm 1766$ \\
\hline
\end{tabular}

a,b Values with different superscripts in a row differ significantly $(P<0.05)$

Table 4: Maturation analysis of female $C$. macrocephalus with different ZnAA levels (mean \pm SE).

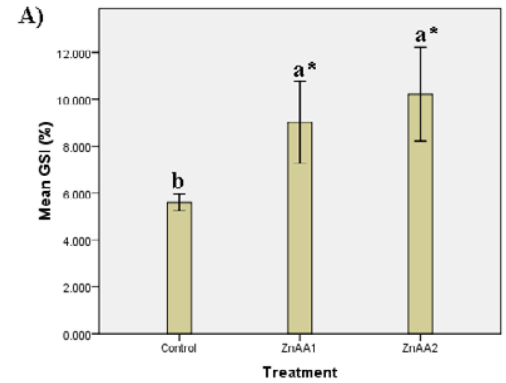

B)
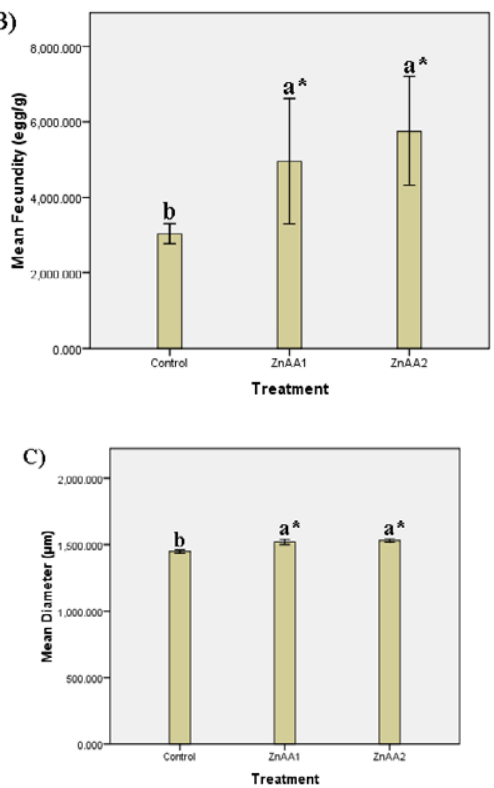

Figure 3: Mean gonadosomatic index (A), fecundity (B) and egg diameter (C) of female $C$. macrocephalus after eight weeks of ZnAA treatment. Values are expressed as mean \pm SEM (GSI N: 6 animals/replicate, fecundity N: 6 animals/ replicate, egg diameter N: 180 eggs/replicate). $p<0.05$.

analysis indicated that a higher number of vitellogenic and matured follicles in ovaries were found in $\mathrm{ZnAA}$ treated treatment (ZnAA1 and ZnAA2). After eight weeks of ZnAA experiment trial, the female broodstock were artificially fertilized with semen from control males to evaluate the reproductive performance. The fertilization rate of the ZnAA treated fertilized female ZnAA1 and ZnAA2 were significantly higher $(\mathrm{p}=0.045)$ compared to the control groups (Figure $4 \mathrm{~A}$ and Table 5). There was higher number of larval survival rate observed in females broodstock exposed in ZnAA treatment for C. macrocephalus with a $P$ value at 0.001 (Figure $4 \mathrm{~B}$ and Table 5). However, the $\mathrm{ZnAA}$ treatment has no significant different in the fecundity and hatching rate
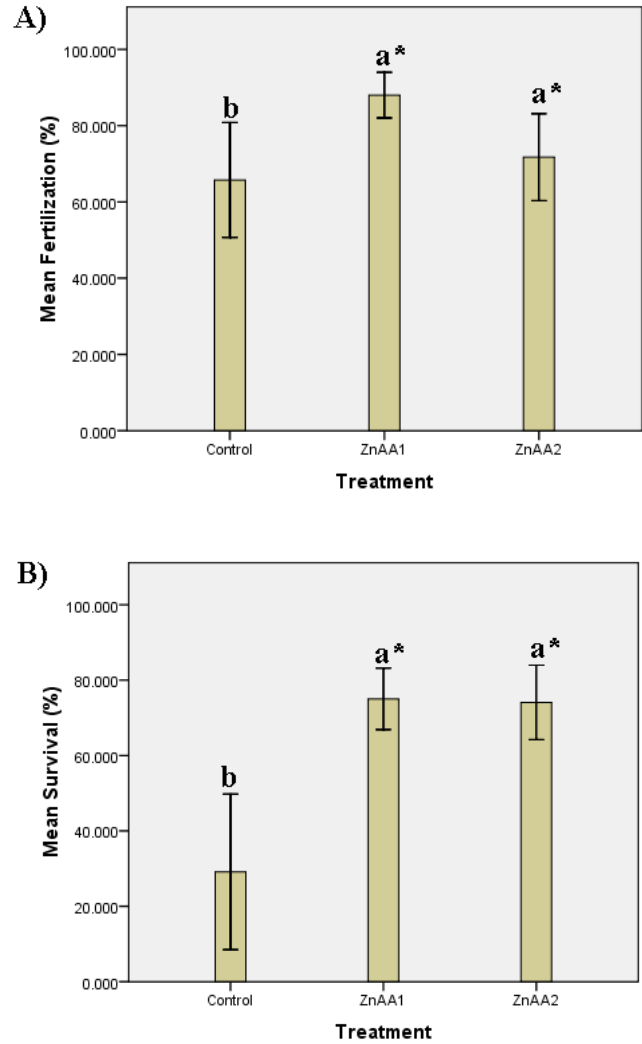

Figure 4: Mean spawning fertilization rate $(A)$ and survival rate $(B)$ after eight weeks of $\mathrm{ZnAA}$ treatment. Values are expressed as mean \pm SEM $p<0.05$.

with the $\mathrm{P}$ value at 0.2 , and 0.7 , respectively. After the first breeding session, the fertilized female broodstock continued to be fed with trial feed for another four weeks and were artificially fertilized with semen from control males to evaluate the recovery reproductive performance. There was higher percentage of female that ready to breed observed in $\mathrm{ZnAA}$ exposed treatment with the percentage at 50\% (Control), $71.4 \%$ (ZnAA1) and $87.5 \%$ (ZnAA2) (Table 6). The fecundity and hatching rate of the all ZnAA treatments were significantly higher with the $\mathrm{P}$ value at 0.001 , and 0.025 , compared to the control groups (Figure 5 and Table 6). However, the ZnAA treatment has no significant effects in the larval survival rate $(\mathrm{p}=0.3)$ (Table 6).

\section{Discussion}

In this study, $\mathrm{ZnAA}$ accumulations were found to be significantly 


\begin{tabular}{|l|c|c|c|c|}
\hline Treatment & Control & ZnAA1 & ZnAA2 & $\boldsymbol{P}$ value \\
\hline Fertilization Rate (\%) & $65.75^{\mathrm{b}} \pm 21$ & $88^{\mathrm{a}} \pm 7.9$ & $72^{\mathrm{a}} \pm 16$ & 0.045 \\
\hline Survival rate (\%) & $29.1^{\mathrm{b}} \pm 17.9$ & $75^{\mathrm{a}} \pm 11$ & $74^{\mathrm{a}} \pm 13$ & 0.001 \\
\hline Hatching rate (\%) & $10.5 \pm 8$ & $14.3 \pm 14$ & $16 \pm 13$ & 0.7 \\
\hline Egg production $(\mathrm{egg} / \mathrm{kg})$ & $2105 \pm 1045$ & $2715 \pm 973$ & $3371 \pm 1997$ & 0.2 \\
\hline
\end{tabular}

a,b Values with different superscripts in a row differ significantly $(P<0.05)$

Table 5: Breeding performance of female C. macrocephalus with different ZnAA levels (Mean $\pm \mathrm{SE}$ ).

\section{A)}
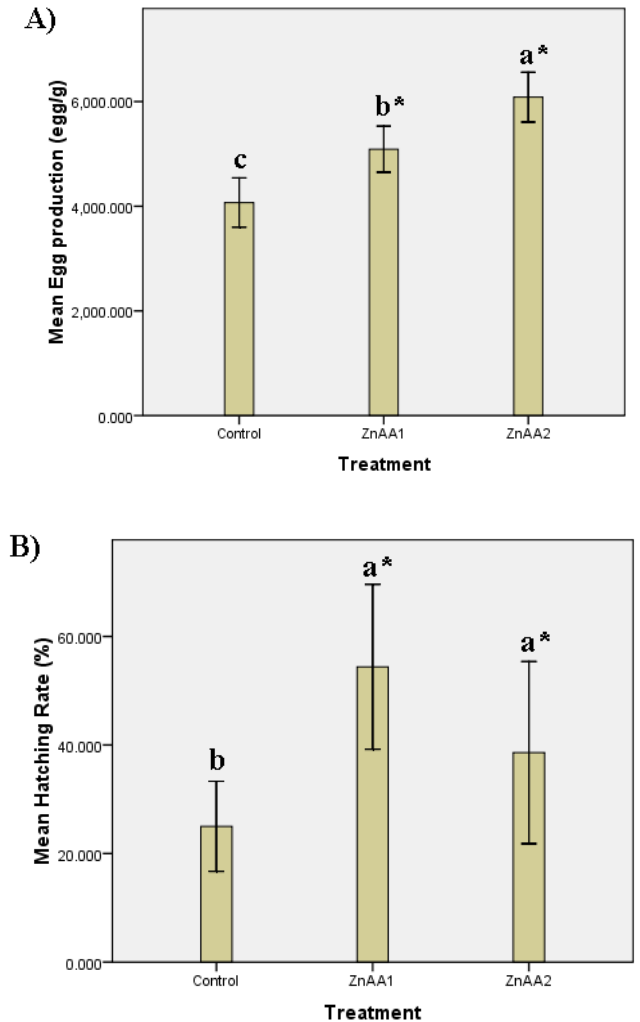

Figure 5: Mean egg production (A) and hatching rate (B) from the recovery breeding session. Values are expressed as mean \pm SEM $p<0.05$.

\begin{tabular}{|l|c|c|c|c|}
\hline Treatment & Control & ZnAA1 & ZnAA2 & $P$ value \\
\hline Breeding broodstock (\%) & $50 \%$ & $71.4 \%$ & $87.5 \%$ & - \\
\hline Egg production(egg/kg) & $4069.5^{\mathrm{c}} \pm 472$ & $5644.8^{\mathrm{b}} \pm 493$ & $6499^{\mathrm{a}} \pm 630$ & 0.001 \\
\hline Hatching rate (\%) & $25^{\mathrm{b}} \pm 36$ & $54^{\mathrm{a}} \pm 29$ & $39^{\mathrm{a}} \pm 30$ & 0.025 \\
\hline Survival Rate (\%) & $40.7 \pm 9$ & $54.3 \pm 27$ & $46.5 \pm 25$ & 0.6 \\
\hline
\end{tabular}

a,b,c Values with different superscripts in a row differ significantly $(P<0.05)$

Table 6: Recovery breeding performance of female $C$. macrocephalus with different ZnAA levels (Mean \pm SE).

different in serum, meat and ovary. According to Thompson et al. [21], exogenous ZnAA was then absorbed by intestine to the liver and was passed on to the ovary during reproductive development. This mechanism is regulated with metal-binding protein metallo thionein in the liver where the primary function of metallo thionein is to control a pool of loosely ligated ZnAA within the cell. In other study, Thompson et al. [21] stated that $\mathrm{ZnAA}$ is accumulated in the liver and transported by the bloodstream to other organs. Thus, it explains the significant increase of $\mathrm{ZnAA}$ in ovary in the current study. The $\mathrm{ZnAA}$ accumulation in other parts of the treated female such as bone suggested that zinc stimulates bone formation [22]. Zinc also helps bone mineralization by acting as a cofactor for alkaline phosphatase [23]. In this study, the estradiol profile in the C. macrocephalus female broodstock was not significant with ZnAA treatment compared to the control group. Usually, estradiol is secreted into the bloodstream to the liver and stimulates the synthesis of vitellogenin production by hepatocytes [24]. In teleost, estradiol concentration gradually elevates during vitellogenesis and declines in response of luteinizing hormone (GTH-II) as oocytes begin their maturation $[9,25]$. Thus, it explains the insignificant difference of estradiol profile in this study. The level of GSI, fecundity, egg diameter and mature cells in histology analysis from the ZnAA treated group demonstrated a significant difference compared to the control group. Previous studies demonstrated that the estradiol induced vitellogenesis process in the liver [24]. Vitellogenesis is a process where vitellogenin is transported from the liver via the bloodstream to the ovary. In ovary, vitellogenin is incorporated by a receptor-mediated process into subsequently nourishing the developing embryo [21,26,27]. Vitellogenin is also known as zinc bounded protein [27]. The role of $\mathrm{ZnAA}$ protein is essential as cofactor for enzymes which are involved in DNA, RNA and protein synthesis as well as a requirement for membrane and polyribosome stability [8]. During vitellogenesis, oocytes increase in size, thus it explains the significant increase in GSI, fecundity, egg diameter and prominent mature cells in histology analysis. ZnAA metallo thionein influences the reproductive cycle by being involve in the hepatic synthesis of a yolk precursor (vitellogenin) and induces oocytes growth prior to fertilization. According to Banks et al. [8], vitellogenin are transported via the blood to the growing oocytes and processed, for the developing embryo and larvae after fertilization. In the present study, the fertilization rate and survival rate of the $\mathrm{ZnAA}$ treated fertilized female were significantly higher compare to the control group. According to Riggio et al. [28], the role for zinc during embryonic development had to act as a regulator of cell division and morphogenesis. While zinc application enhances the cell proliferation, zinc deprivation reduces cell division and stimulates congenital abnormalities of foetal organs derived from ectodermal, mesodermal and endodermal germ lines $[5,28]$. In recovery reproductive performance, the $\mathrm{ZnAA}$ treatment groups demonstrated a higher percentage of female that prompt to spawn. The other parameter such as fecundity and hatching rate showed a significant difference from the control group. The female broodstock in recovery experiment were fed with $\mathrm{ZnAA}$ treatment have longer duration. This condition favours more $\mathrm{ZnAA}$ accumulation in the liver thus, increased the levels of $\mathrm{ZnAA}$ metallothionein for vitellogenesis. The vitellogenesis produces vitellogenin in the liver and transports it to the ovary and nourishing the developing embryo [21].

\section{Conclusion}

The recent study indicated that the optimum zinc amino acid treatment in enhancing the Clarias macrocephalus female broodstock first sexual maturation and improving the reproductive performance is ZnAA1 (100 ppm ZnAA).

\section{Acknowledgement}

The authors would like to thank the members of Laboratory of Nutrition and Aquafeed, Department of Aquaculture, Faculty of Fisheries, Kasetsart University Bangkok for the assistance during this study. This study was funded by Ministry of Education, Malaysia.

\section{References}

1. Petkam R, Moodie GEE (2001) Food particle size, feeding frequency, and the use of prepared food to culture larval walking catfish (Clarias macrocephalus). Aqua 194: 349-362. 
Citation: Aripin SA, Jintasataporn O, Yoonpundh R (2015) Effects of Zinc Amino Acid in Walking Catfish (Clarias macrocephalus) Female Broodstock First Sexual Maturation. J Aquac Res Development 6: 347. doi:10.4172/2155-9546.1000347

2. Areerat $S$ (1987) Clarias culture in Thailand. Aqua 63: 355-362.

3. Na-Nakorn U, Kamonrat W, Ngamsiri T (2004) Genetic diversity of walking catfish, Clarias macrocephalus, in Thailand and evidence of genetic introgression from introduced farmed C. gariepinus. Aqua 240: 145-163.

4. Baker DH, Ammerman CB (1995) Zinc bioavailability. In Bioavailability of nutrients for animals: amino acids, minerals and vitamins.

5. Black RE (2001) Micronutrients in pregnancy. Br J of Nutr 85: 193-197.

6. Salgueiro MJ, Zubillaga M, Lysionek A, Sarabia MI, Care R, et al (2000) Zinc as an Essential Micro Nutrient: A Review. Nutr Res 20: 737-755.

7. Thompson ED, Mayer GD, Balesaria S, Glover CN, Walsh PJ, et al. (2003) Physiology and endocrinology of zinc accumulation during the female squirrelfish reproductive cycle. Comp Biochem Physiol part A 134: 819-828.

8. Banks SD, Thomas P, Baer KN (1999) Seasonal variations in hepatic and ovarian zinc concentrations during the annual reproductive cycle in female channel catfish (Ictalurus punctatus). Comp Biochem Physiol Part C 124 65-72.

9. Aizen J, Kowalsman N, Niv MY, Levavi-Sivan B (2014) Characterization of tilapia (Oreochromis niloticus) gonadotropins by modelling and immunoneutralization. General and Comparative Endocrinology 207: 28-33.

10. Formigoni A, Fustini M, Archetti L, Emanuele S, Sniffen C, et al. (2011) Effects of an organic source of copper, manganese and zinc on dairy cattle productive performance, health status and fertility. Animal Feed Science and Technology 164: 191-198.

11. Garg AK, Mudgal V, Dass RS (2008) Effect of organic zinc supplementation on growth, nutrient utilization and mineral profile in lambs. Animal Feed Science and Technology 144: 82-96.

12. NRC (2011) Nutrient Requirements of Fish. National Academies Press, Washington.

13. Xie N, Huang J, Li B, Cheng J, Wang Z, et al. (2015) Affinity purification and characterisation of zinc chelating peptides from rapeseed protein hydrolysates: Possible contribution of characteristic amino acid residues. Food Chemistry 173: 210-217.

14. Drury RA, Wallington EA (1967) Carleton's Histological Technique. Oxford University Press, Oxford.
15. Lubzens E, Young G, Bobe J, Cerda J (2010) Oogenesis in teleost: how eggs are formed. General and Comparative Endocrinology 165: 367-389.

16. Ibrahim ATA Harabawy ASA (2014) Sublethal toxicity of carbofuran on the African catfish Clarias gariepinus: Hormonal, enzymatic and antioxidant responses. Ecotoxicology and Environmental Safety 106: 33-39.

17. Fermin AC (1991) LHRH-a and domperidone-induced oocytes maturation and ovulation in bighead carp, Aristichthys nobilis (Richardson). Aqua 93: 87-94.

18. Bagenal TB (1978) Aspects of Fish Fecundity. In Ecology of Freshwater Fish Production, Blackwell Scientific Publications, Oxford.

19. Unuma T, Kondo S, Tanaka H, Kagawa H, Nomura K, et al. (2004) Determination of the rates of fertilization, hatching and survival in the Japanese eel, Anguilla japonica, using tissue culture microplates. Aqua 241: 345-356.

20. Gomez KA, Gomez AA (1984) Statistical procedures in agricultural research, Wiley, New York.

21. Thompson ED, Mayer GD, Walsh PJ, Hogstrand C (2002) Sexual maturation and reproductive zinc physiology in the female squirrelfish. The Journal of Experimental Biology 205: 3367-3376.

22. Sa MVC, Pezzato LE, Lima MMBF, Padilha PM (2004). Optimum zinc supplementation level in Nile tilapia Oreochromis niloticus juveniles diets. Aqua 238: 385-401.

23. Yamaguchi M (1998) Role of zinc in bone formation and bone resorption. The Journal of Trace Elements in Experimental Medicine 11: 119-135.

24. Sun B, Pankhurst NW (2006) In vitro effect of vitellogenin on steroid production by ovarian follicles of greenback flounder Rhombosolea tapirina. Comp Biochem Physiol Part A 144: 78-85.

25. Devlin RH, Nagahama Y (2002) Sex determination and sex differentiation in fish: an overview of genetic, physiological, and environmental influences. Aqua 208: 191-364.

26. Falchuk KH, Montorzi M, Vallee BL (1995) Zinc uptake and distribution in Xenopus laevis oocytes and embryos. Biochem 34: 16524-16531.

27. Montorzi M, Falchuk KH, Vallee BL (1995) Vitellogenin and lipovitellin: zinc proteins of Xenopus laevis oocytes. Biochem 34: 10851-10858.

28. Riggio M, Filosa S, Parisi E, Scudiero R (2003) Changes in zinc, copper and metallothionein contents during oocytes growth and early development of the teleost Danio rerio (zebrafish). Comp Biochem Physiol Part C 135: 191-196. 